\title{
Association between the type of thyroid dysfunction induced by immune checkpoint inhibitors and prognosis in cancer patients
}

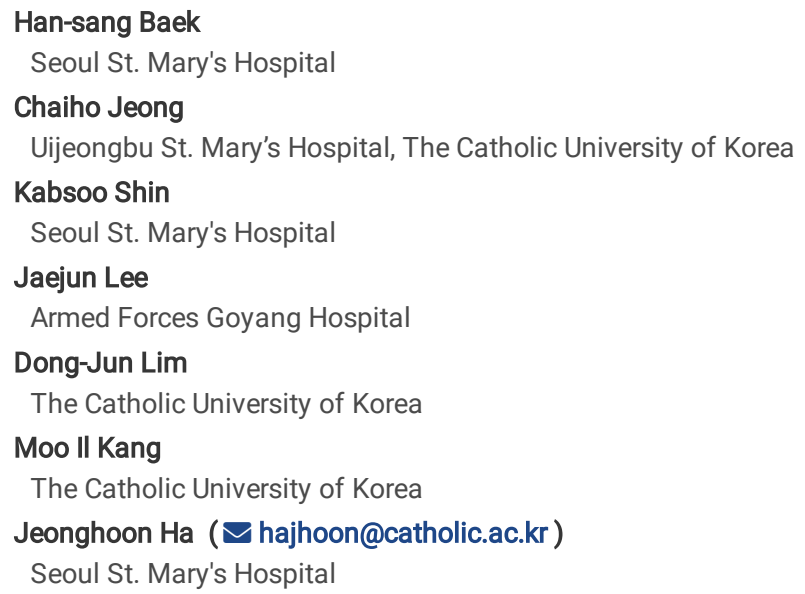




\section{Abstract \\ Background}

Immune checkpoint inhibitors (ICls) cause thyroid immune-related adverse effects (irAEs). However, associations between each type of thyroid immune-related adverse effect (irAE) and the anti-tumor effect of $\mathrm{ICI}$ remains unknown. This study aimed to determine the effects of each type of thyroid dysfunction on patient survival.

\section{Methods}

Patients who initiated ICI treatment from January 2015 to December 2019 in Seoul St. Mary's Hospital were retrospectively analyzed. Thyroid dysfunction was classified into four types: newly developed overt or subclinical hypothyroidism, thyrotoxicosis, worsened hypothyroidism, and subclinical hyperthyroidism. Patients were divided into two groups according to the presence or absence of thyroid dysfunction.

\section{Results}

Among the 196 patients, 66 (33.7\%) developed thyroid irAEs. There was no significant difference in age, sex, or cancer type between the two groups. The overall survival in patients with thyroid irAEs was significantly higher than that in patients without thyroid irAEs (38 months vs. 13 months, respectively, $p=$ 0.005 ). After adjusting for confounding factors, the hazard ratio for mortality in the thyroid irAE group compared to the no thyroid irAE group was 0.520 ( $p=$ 0.007). Newly developed overt or subclinical hypothyroidism patients showed a significantly lower hazard ratio for morbidity of $0.309(p=0.001)$. Patients with thyrotoxicosis showed a worse hazard ratio for morbidity than those without thyroid irAE, although the difference was not statistically significant.

\section{Conclusions}

It was verified that ICl treatment-induced thyroid dysfunction was associated with better survival, even in the real-world practice. Thus, endocrinologists should cooperate with oncologists to monitor patients treated with ICls.

\section{Introduction}

Complex interactions between various types of immune cells are required to elicit an effective cytotoxic immune response against tumor cells [1-4]. Recently, a number of methods for treating malignancies by controlling the cytotoxic immune response have been reported [5-7]. Immune checkpoint inhibitors (ICls) are immunomodulatory antibodies that are most commonly used to treat advanced malignancies. Programmed cell death 1 (PD-1) inhibitors and programmed cell death ligand 1 (PD-L1) inhibitors are the types of ICls. They show anti-cancer effects by blocking the PD-1:PD-L1 interaction; thus, allowing T cells to induce tumor cell death [8]. PD-1 inhibitors (such as pembrolizumab and nivolumab) and PD-L1 inhibitors (such as atezolizumab and duvalumab) used in clinical fields have shown improved prognosis [9-15].

Immune-related adverse effects (irAEs) are known to affect endocrine organs, such as the pituitary, thyroid, and pancreas [16-19]. Thyroid dysfunction is especially associated with the use of PD-1 or PD-L1 inhibitors [20-23]. In a systematic review and meta-analysis of patients treated with nivolumab, pembrolizumab, or atezolizumab, the incidence of hypothyroidism was $7.0 \%, 3.9 \%$, and $13.2 \%$, and that of hyperthyroidism was $3.2 \%, 0.6 \%$, and $8 \%$, respectively [24]. Interestingly, patients with irAEs showed improved prognosis compared to those without irAEs [25]. Kotwal et al. [26] showed that patients with thyroid irAEs had longer overall survival and lower mortality, although they only focused on patients treated with PD-L1 inhibitors rather than PD-1 inhibitors.

From previous studies, it could be assumed that thyroid irAEs were associated with prognosis, and some factors were associated with thyroid irAEs [26, 27]. However, those previous studies were mostly based on clinical trials or specific populations with a focus on a particular ICI in each study. Although there are many studies on the associations between each type of thyroid irAE and ICI treatment, there is a lack of studies addressing associations between each type of thyroid irAE and prognosis. Furthermore, there is a need to investigate whether similar results can be obtained in a different population. Therefore, this study aimed to determine the association between each type of thyroid irAE induced by ICls and survival using real-world practice data.

\section{Materials And Methods}

\section{Study population}

Data of patients who had initiated PD-L1 or PD-1 treatment from January 2015 to December 2019 in Seoul St. Mary's Hospital with thyroid function laboratory tests were retrospectively reviewed. The oncologist determined the selection of the ICls or treatment schedules. Patients who had no follow-up data of the thyroid function test after ICl treatment initiation and those who had thyrotropin (a thyroid-stimulating hormone [TSH]) suppression treatment for thyroid cancer were excluded. Patients who underwent sequential ICl switching or combination therapy were also excluded because it was unclear which ICI could affect the result. Patients who were included in the clinical trials were also excluded because it was difficult to confirm the ICl schedule was based on medical records. During the study period, a total of 219 patients who received ICI treatment had laboratory data for thyroid function tests. Among them, 23 patients were excluded (11 had no follow-up data, six had TSH suppression test for thyroid cancer, 3 were in clinical trials, and 3 had sequential or combination ICI 
treatment). After excluding these 23 patients, 196 patients were finally selected for the analysis (Fig. 1). Approval for this study was obtained from the institutional review board of St. Mary's hospital (KC21RASI0620)

\section{Treatmens definitions and classification}

ICI treatment time was defined as the time from the ICI initiation date to the last ICI treatment date. Thyroid autoantibody positivity was defined as the ratio of the number of patients who had a higher value of anti-microsomal-antibody (TPO-Ab) or thyroglobulin antibody (Tg-Ab) than the cutoff to the number of patients who had thyroid an autoantibody laboratory test. Thyroid dysfunction was classified into four types: 1) newly developed overt hypothyroidism patients who had TSH $\geq 4.8 \mathrm{mlU} / \mathrm{mL}$ and free T4 $<0.89 \mathrm{ng} / \mathrm{mL} ; 2)$ thyrotoxicosis - patients who had suppressed TSH ( $<0.5 \mathrm{mlU} / \mathrm{mL})$ and increased free T4 $(>1.8 \mathrm{ng} / \mathrm{mL})$; 3) worsened hypothyroidism - patients who had an increased dose of T4 replacement after ICI treatment; and 4) subclinical hyperthyroidism patients who had suppressed TSH $(<0.5 \mathrm{mIU} / \mathrm{mL})$ and normal level of free T4 $(0.89$ to $1.76 \mathrm{ng} / \mathrm{mL})$. The classification was based on laboratory test done after finishing $\mathrm{ICl}$ treatment cycles. Patients were divided into two groups: those who had any thyroid dysfunction mentioned above and those who did not have any thyroid dysfunction. After checking the medical records, no patients had worsened hyperthyroidism. Thus, thyroid dysfunction types were divided into four groups.

\section{Laboratory test}

The thyroid function test was performed in two ways: 1) using the BECKMAN immunoradiometric assay (IMRA) kit (Immunotech, Prague, Czech Republic), and 2) using the ADIVA Centaur electrochemiluminescence immunoassay (ECLIA) kit (Siemens Healthcare Diagnostic Inc. USA). All laboratory tests were performed at St. Mary's Hospital, Seoul, Korea. Normal ranges were as follows: TSH of 0.55 to $4.78 \mathrm{ulU} / \mathrm{mL}$ in ECLIA and of 0.17 to $4.05 \mathrm{IU} / \mathrm{mL}$ in IMRA, free T4 of 0.89 to $1.76 \mathrm{ng} / \mathrm{mL}$ in both IRMA and ECLIA, T3 of 0.6 to $1.81 \mathrm{ng} / \mathrm{mL}$ in ECLIA and 1.2 to $2.7 \mathrm{nmol} / \mathrm{L}$ in IRMA. The cutoff positivity for anti-microsomalantibody (TPO-Ab) and thyroglobulin antibody (Tg-Ab) was $60 \mathrm{U} / \mathrm{mL}$ in both tests.

\section{Statistical analysis}

The two groups of patients (those with any thyroid dysfunction and those who did not have any thyroid dysfunction) were compared using the t-test or chisquared test. Fisher's exact test was performed when the sample size was small. Kaplan-Meier curves were used to obtain overall survival using the log-rank $p$ value. The Cox proportional-hazards model was used to adjust for confounding factors. SPSS ${ }^{R}$ v.24 (IBM Corp., New York, NY; formerly SPSS Inc., Chicago, IL, USA) was used for all statistical analyses.

\section{Results}

\section{Thyroid dysfunction and overall survival}

Patients who received pembrolizumab $(n=106)$, nivolumab $(n=68)$, or atezolizumab $(n=22)$ were analyzed. Among these 196 patients, $66(33.7 \%)$ developed thyroid irAEs. The median age was $66.7 \pm 10.7$ years for those with thyroid irAE and $63.8 \pm 11.2$ years $(p=0.088)$ for those who had no thyroid irAE. The most common malignancy type was lung cancer in both groups, showing no significant difference between the two groups: 44 (66.7\%) in the thyroid irAE group and $74(56.9 \%)$ in the no thyroid irAE group ( $p=0.362)$. Twenty-three (34.8\%) patients in the thyroid irAE group and 65 (50.0\%) in the no thyroid irAE group had confirmed death by medical records $(p=0.044)$. During the study period, ICls were mostly used in the advanced stage of malignancy in our center. Despite that, ICl treatment time was longer in the thyroid irAE group (7.4 \pm 7.7 months vs. $4.1 \pm 6.8$ months, $p=0.002)$. Time from ICI treatment initiation to death or the last follow up date was significantly longer in the thyroid irAE group ( $13.7 \pm 10.6$ months vs. $9.7 \pm 10.0$ months, $p=0.01)$. There was no significant difference in body mass index (BMI) between the two groups (Table 1). The overall survival in patients in the thyroid irAE group was significantly higher than that in patients in the no thyroid irAE group $(p=0.005)$. Three-year survival rate was $34.8 \%$ in the thyroid irAE group and $25 \%$ in the no thyroid irAE group $(p=0.55)$. The median follow-up duration was 11.5 months. The median survival time was $13 \pm 1.6$ months in the no thyroid irAE group and $38 \pm 11.0$ months in the thyroid irAE group (Fig. 2). 
Baseline characteristics of patients after immune checkpoint inhibitor treatment

\begin{tabular}{|c|c|c|c|}
\hline & Thyroid irAE $(\mathrm{N}=66)$ & No thyroid irAE $(N=130)$ & $p$ value \\
\hline Age (years) ${ }^{a}$ & $66.7 \pm 10.7$ & $63.8 \pm 11.2$ & 0.088 \\
\hline Male, n (\%) & $49(74.2 \%)$ & $93(71.5 \%)$ & 0.689 \\
\hline $\mathrm{BMI}\left(\mathrm{kg} / \mathrm{m}^{2}\right)$ & $23.1 \pm 3.0$ & $22.1 \pm 4.0$ & 0.078 \\
\hline Underlying malignancy, n (\%) & & & 0.362 \\
\hline lung & $44(66.7 \%)$ & $74(56.9 \%)$ & \\
\hline melanoma & $5(7.6 \%)$ & $19(14.6 \%)$ & \\
\hline urothelial cancer & $3(4.5 \%)$ & $5(3.8 \%)$ & \\
\hline breast & $0(0 \%)$ & $1(0.8 \%)$ & \\
\hline colon & $0(0 \%)$ & $1(0.8 \%)$ & \\
\hline esophagus & $3(4.5 \%)$ & $0(0.0 \%)$ & \\
\hline $\mathrm{HCC}$ & $1(1.5 \%)$ & $3(2.3 \%)$ & \\
\hline jejunum & $0(0.0 \%)$ & $1(0.8 \%)$ & \\
\hline mesothelioma & $1(1.5 \%)$ & $4(3.1 \%)$ & \\
\hline head and neck cancer & $1(1.5 \%)$ & $8(6.2 \%)$ & \\
\hline ovary & $0(0.0 \%)$ & $1(0.8 \%)$ & \\
\hline pancreas & $1(1.5 \%)$ & $0(0.0 \%)$ & \\
\hline renal & $2(3.0 \%)$ & $2(3.0 \%)$ & \\
\hline skin & $0(0.0 \%)$ & $1(0.8 \%)$ & \\
\hline stomach & $4(6.1 \%)$ & $9(6.9 \%)$ & \\
\hline thymoma & $1(1.5 \%)$ & $1(0.8 \%)$ & \\
\hline Immune check point inhibitor, $\mathrm{n}(\%)$ & & & 0.169 \\
\hline pembrolizumab & $41(62.1 \%)$ & $65(50.0 \%)$ & \\
\hline nivolumab & $17(25.8 \%)$ & $51(39.2 \%)$ & \\
\hline atezolizumab & $8(12.1 \%)$ & $14(10.8 \%)$ & \\
\hline Death, n (\%) & $23(34.8 \%)$ & $65(50 \%)$ & 0.044 \\
\hline Treatment duration ${ }^{\mathrm{b}}$ (month) & $7.4 \pm 7.7$ & $4.1 \pm 6.8$ & 0.002 \\
\hline Period from initiation of $\mathrm{ICI}$ treatment to death (month) & $13.7 \pm 10.6$ & $9.7 \pm 10.0$ & 0.010 \\
\hline \multicolumn{4}{|c|}{ irAE immune related adverse event, $B M /$ body mass index, $H C C$ hepatocellular carcinoma, $I C /$ immune check point inhibito } \\
\hline \multicolumn{4}{|l|}{${ }^{\mathrm{a}} \mathrm{Age}$ at ICl initiation } \\
\hline 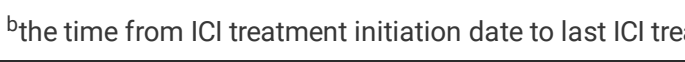 & ent date. & & \\
\hline
\end{tabular}

\section{Patient Prognosis According To Each Type Of Thyroid Dysfunction}

In subgroup analysis, the overt hypothyroidism group and the worsened hypothyroidism group showed significantly longer ICI treatment time and duration from ICI initiation to death or the last follow-up. There was still no difference in BMI among the thyroid irAE groups. The period thyrotoxicosis or subclinical hyperthyroidism group were diagnosed was shorter than period of diagnosis to hypothyroidism (Table 2). Of 40 overt or subclinical hypothyroidism group, 13 were proceed from thyrotoxicosis or subclinical hyperthyroidism. After adjusting for age, sex, and cancer type, the hazard ratio for mortality in the thyroid irAE group compared to that in the no irAE group was $0.477(p=$ 
0.005). In subgroup analysis, the newly developed overt hypothyroidism groups showed significant improvement in prognosis. The hazard ratio for morbidity according to the type of ICl showed no significant differences (Table 3, Fig. 3). Patients with thyrotoxicosis showed a worse hazard ratio for morbidity compared to those in the no thyroid irAE group, although the difference between the two groups was not statistically significant. More detailed characteristics of the six patients with thyrotoxicosis are summarized in Supplementary table 1. Among these six patients with thyrotoxicosis, three had lung cancer, two melanoma, and one thymoma. Two patients were treated with atezolizumab, and four of them were treated with pembrolizumab. Two patients showed high levels of thyroid autoantibodies. ICI treatment was changed to another regimen due to thyrotoxicosis in one patient. In the other three patients, ICl treatment was continued and later stopped because of tumor progression. The thyroid autoantibody positivity did not show a statistically significant difference between the thyroid irAE and no thyroid irAE groups ( $p=0.138$ for TPO Ab and $p=0.294$ for Tg-Ab) (Table 4). 
Table 2

Subgroup analysis according to the type of thyroid dysfunction

No
thyroid

irAE Newly

developed

$(\mathrm{N}=\quad$ overt

130)

hypothyroidism

Thyrotoxicosis

$(N=6)$
Worsened

hypothyroidism

$(\mathrm{N}=4)$
Subcliniı

hyperthy

$(\mathrm{N}=16)$

$\begin{array}{llllll}\text { Age } & 63.8 \pm & 65.2 \pm 12.5 & 65.5 \pm 6.2 & 70.0 \pm 7.8 & 69.9 \pm 6 . \\ \text { (years) }^{a} & 11.2 & & & \end{array}$

Male, $\mathbf{n}$

(\%)

93

$(71.5$

$\%)$

$4(66.7 \%)$

$1(25 \%)$

12 (75\%

BMI

$\left(\mathrm{kg} / \mathrm{m}^{2}\right)$

$22.1 \pm \quad 23.2 \pm 2.7$

$23.3 \pm 3.6$

$20.0 \pm 2.7$

$23.6 \pm 3$

Death, $\mathbf{n}$

65

(\%)

(50\%)

$11(27.5 \%)$

$4(66.7 \%)$

$2(50 \%)$

$6(37.5 \%$

Treatment

time $^{b}$

$4.1 \pm$

$8.9 \pm 8.0$

$2.7 \pm 2.5$

$11.0 \pm 7.6$

$4.7 \pm 7.1$

(month)

Period

from

6.8

initiation

of $\mathrm{ICl}$

treatment

to death

(month)

irAE immune related adverse event, $B M I$ body mass index, $H C C$ hepatocellular carcinomi check point inhibitor

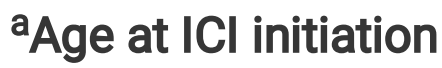

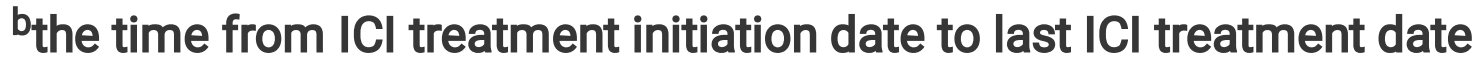

CIt is same as period from initiation of $\mathrm{ICl}$ treatment to death or last follow up because th not occur 


\begin{tabular}{|c|c|c|c|c|c|}
\hline & \multirow{2}{*}{$\begin{array}{l}\text { No } \\
\text { thyroid } \\
\text { irAE } \\
(\mathrm{N}= \\
130)\end{array}$} & \multicolumn{4}{|c|}{ Thyroid irAE (N = 66) } \\
\hline & & $\begin{array}{l}\text { Newly } \\
\text { developed } \\
\text { overt } \\
\text { hypothyroidism } \\
(N=40)\end{array}$ & $\begin{array}{l}\text { Thyrotoxicosis } \\
(N=6)\end{array}$ & $\begin{array}{l}\text { Worsened } \\
\text { hypothyroidism } \\
(\mathrm{N}=4)\end{array}$ & $\begin{array}{l}\text { Subclini } \\
\text { hyperthy } \\
(N=16)\end{array}$ \\
\hline $\begin{array}{l}\text { Period } \\
\text { from } \\
\text { initiation } \\
\text { of ICl } \\
\text { treatment } \\
\text { to } \\
\text { diagnosis } \\
\text { of irAE } \\
\text { (day) }\end{array}$ & $\begin{array}{l}310.0 \\
\pm \\
26.60^{c}\end{array}$ & $128.4 \pm 24.8$ & $113.2 \pm 57.8$ & $45.5 \pm 9.8$ & $84.2 \pm 4$ \\
\hline
\end{tabular}

irAE immune related adverse event, $B M I$ body mass index, $H C C$ hepatocellular carcinomi check point inhibitor

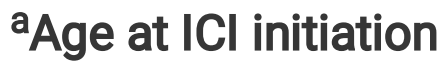

bthe time from ICI treatment initiation date to last ICI treatment date

Clt is same as period from initiation of $\mathrm{ICI}$ treatment to death or last follow up because th not occur 
Table 3

Cox proportional-hazards model for mortality in patients treated with immune checkpoint inhibitors

Variables

Hazard ratio for

P value mortality

Thyroid irAE compared to no thyroid irAE

$0.477(0.284-0.802)$

0.005

Types of thyroid dysfunction ${ }^{\mathrm{a}}$

Newly developed overt hypothyroidism ( $\mathrm{N}=$ 40)

Thyrotoxicosis $(\mathrm{N}=6)$

$2.237(0.797-6.281)$

0.126

Worsened hypothyroidism $(\mathrm{N}=4)$

$0.480(0.110-2.093)$

0.406

Subclinical hyperthyroidism $(\mathrm{N}=16)$

$0.623(0.261-1.484)$

0.246

Male compared to female

$0.922(0.551-1.543)$

0.757

Nivolumab ${ }^{b}$

$1.210(0.746-1.961)$

0.440

Atezolizumab ${ }^{b}$

2.069 (0.947-4.523)

0.068

irAE immune related adverse event, $I C l$ immune check point inhibitor

aall compared to no thyroid irAE

bCompared to pembrolizumab 


\section{Table 4}

Association between TPO-Ab or TG-Ab and thyroid immune related adverse effect and subgroup analysis

\section{Positive TPO-Ab $(\mathrm{N}=19)$}

Negative TPO-Ab

$(N=63)$
P.

value

\section{Presence of thyroid irAE}

0.138

\section{Thyroid irAE}

No thyroid irAE

Type of thyroid irAE
9 (47.4\%)

$10(52.6 \%)$
19 (30.2\%)

$44(71.0 \%)$

\section{Newly developed overt hypothyroidism}

Thyrotoxicosis

Worsened hypothyroidism

Subclinical hyperthyroidism
$4(21.1 \%)$

2 (10.5\%)

3 (15\%)

$0(0 \%)$
$14(22.2 \%)$

0.876

\section{Among 196 study population, TPO-Ab were achieved in 82 patients;}

\section{$T P O-A b$ anti-microsomal-antibody, irAE immune related adverse effect}

\section{Discussion}

In our study, the thyroid irAE group showed better prognosis than the no thyroid irAE group, regardless of age, sex, ICl, or type of underlying malignancy. In particular, the newly developed hypothyroidism group showed a significantly better prognosis.

In our study, $33.7 \%$ of patients developed thyroid irAEs. Although the occurrence rate was slightly different from those in other studies [24, 26,28$]$, the occurrence rate in our study was similar to that in the existing literature. The actual prevalence of thyroid dysfunction could be higher because we only included patients who underwent thyroid function tests at ICI treatment initiation. Because most practice was performed by oncologists and not endocrinologists, thyroid function tests were often omitted.

The patients in the thyroid dysfunction group, especially those with newly developed overt hypothyroidism, showed better prognosis than patients in the no thyroid irAE group. Even after adjusting for sex, age, and cancer type, this same result was consistently obtained. Similar results have been reported extensively [26, 27, 29, 30]. However, these studies either included relatively small numbers of patients or included those with only a specific cancer type or treated with a particular ICl regimen. Kotwal et al. showed improved survival in the thyroid dysfunction group, although they only included patients treated with a PD-L1 inhibitor [26]. Lima Ferreira et al. recently reported improved survival in patients with thyroid dysfunction due to several cancer types and ICI types [27]. However, none of them showed a difference in the thyroid dysfunction type. Moreover, data from Korean patients have rarely been reported.

Newly developed overt hypothyroidism patients showed significantly lower hazard ratio mortality, whereas the thyrotoxicosis group showed a high hazards ratio. In fact, previous studies shown ICI induced thyrotoxicosis would eventually develop hypothyroidism[28, 31, 32]. In our study, period from ICI initiation to diagnosis of thyrotoxicosis was shorter than period to diagnosis of hypothyroidism. In addition, among 40 hypothyroidism patients, 13 experienced thyrotoxicosis period. However, 6 thyrotoxicosis patients did not show development of hypothyroidism. Because almost their malignancy showed progression, thyroid problem was not concerned.

On the other hand, many studies have suggested that hyperthyroidism was linked to poorer cancer prognosis [33]. However, considering that patients who had already taken a thyroid hormone for hypothyroidism showed better prognosis, the TSH stimulation pathway might be associated with prognosis. The underlying mechanisms involved in thyroid irAE and ICI treatment are not yet fully understood [25]. Thyroid irAEs often manifest as asymptomatic thyrotoxicosis, followed by a rapid transition to hypothyroidism [31]. Intrathyroidal predominance of specific T lymphocytes is thought to be associated with ICl-induced thyroiditis [34]. However, how ICl efficacy and thyroid irAEs are connected remains unknown. Previous studies have suggested that some immune 
pathways involving T cells or NK cells influenced thyroiditis with an anti-cancer effect [21, 22, 35]. However, the underlying mechanisms remain unknown. Moreover, the link between irAEs and anti-tumor effects remains unclear [25].

There is no reliable marker for predicting the prognosis, response, or adverse events after ICI treatment [36]. Recently, in one study in a single center in Korea, a positivity for thyroid autoantibodies could predict the progression to overt hypothyroidism [28]. In a small group study, a low frequency of thyroid autoantibody was observed, suggesting that there might be a different pathogenesis between ICl-induced thyroiditis and classical autoimmune thyroiditis [37]. In our results, thyroid autoantibody positivity was not significantly different between the thyroid irAE group and the no thyroid irAE group. However, in the subgroup comparison, there was a significant difference among the groups. Positive TPO-Ab was associated with levothyroxine dose elevation, and positive Tg-Ab was associated with thyrotoxicosis development. This is similar to the results from a previous study [26, 28]. This suggests that thyroid autoantibodies could predict the course after ICI treatment. Another factor that has drawn our attention was the BMI. Many studies have reported that a higher BMI was associated with better cancer prognosis in a variety of cancer types [38-40]. Wang et al. have shown that although obesity causes were increased immune aging and tumor growth; it also causes PD-1 mediated T cell dysfunction, which led to stronger responses to ICl treatment [41]. Leptin is thought to be involved in this process [42]. Rena et al. reported an association between higher BMI and ICl-induced thyroiditis [43]. However, this was a single-center study that did not analyze the relationship with prognosis. In our study, BMI did not show a significant difference among patients with thyroid dysfunction. In a study by Pollack Rena et al. [39], $20 \%$ of patients had a BMI > 30 . However, only $2.6 \%$ of the patients had a BMI than higher than 30 in our study.

This study has some limitations. First, the study population was heterogeneous due to the retrospective nature of the study. ICI treatment was performed by various oncologists; therefore, thyroid function test was not routinely performed in all cases. A well-designed prospective analysis will overcome these limitations. Second, the median follow-up period was relatively short because the use of ICls was recently started in our center. We could include duvalumab, another PD-L1 inhibitor, because this agent was stated to be used in our hospital in 2020 with a follow-up duration of too short.

In conclusion, it was verified that ICI treatment-induced thyroid dysfunction was associated with better survival in the real-world practice of Korean patients. The overall prognosis was the best when newly developed hypothyroidism occurred, and since TPO-Ab was significantly observed in the occurrence of overt hypothyroidism, the presence or absence of TPO-Ab could be used as a marker to predict patient prognosis in real practice.

\section{Abbreviations}

ICl: Immune checkpoint inhibitors

irAE: immune-related adverse effects

TSH: thyroid-stimulating hormone

TPO-Ab: anti-microsomal-antibody

Tg-Ab: thyroglobulin antibody

BMl: body mass index

\section{Declarations}

\section{Ethics approval and consent to participate}

The study was approved by the institutional review board of St. Mary's hospital (KC21RASI0620). Permission to use hospital data was granted by the institutional review board of St. Mary's hospital.

\section{Consent for publication}

Due to the retrospective nature of the study, the requirement to obtain informed consent was waived by the institutional review board of St. Mary's hospital

\section{Availability of data and materials}

Not applicable

\section{Competing interests}

The authors declare that they have no competing interests.

\section{Funding}

None

\section{Authors' contributions}

Han-Sang Baek, Kabsoo Shi and Jeonghoon Ha mainly designed the study. Han-Sang Baek mainly wrote the manuscript. Jeonghoon Ha supervised the study and is corresponding author. Jaejun Lee contributed to data analysis. All authors contributed to drafting or revising the article, gave final approval of the version to be published, agreed to the submitted journal, and agree to be accountable for all aspects of the work. 


\section{Acknowledgements}

None

\section{References}

1. Bailey SR, Nelson MH, Himes RA, Li Z, Mehrotra S, Paulos CM. Th17 cells in cancer: the ultimate identity crisis. Front Immunol. $2014 ; 5: 276$. https://doi.org/10.3389/fimmu.2014.00276.

2. Gras Navarro A, Björklund AT, Chekenya M. Therapeutic potential and challenges of natural killer cells in treatment of solid tumors. Front Immunol. 2015;6:202. https://doi.org/10.3389/fimmu.2015.00202.

3. Laoui D, Van Overmeire E, De Baetselier P, Van Ginderachter JA, Raes G. Functional Relationship between Tumor-Associated Macrophages and Macrophage Colony-Stimulating Factor as Contributors to Cancer Progression. Front Immunol. 2014;5:489. https://doi.org/10.3389/fimmu.2014.00489.

4. Savage PA, Leventhal DS, Malchow S. Shaping the repertoire of tumor-infiltrating effector and regulatory T cells. Immunol Rev. 2014;259(1):245-58. https://doi.org/10.1111/imr.12166.

5. Gun SY, Lee SWL, Sieow JL, Wong SC. Targeting immune cells for cancer therapy. Redox Biol. 2019;25:101174. https://doi.org/10.1016/j.redox.2019.101174.

6. Waldman AD, Fritz JM, Lenardo MJ. A guide to cancer immunotherapy: from T cell basic science to clinical practice. Nat Rev Immunol. 2020;20(11):65168. https://doi.org/10.1038/s41577-020-0306-5.

7. Hiam-Galvez KJ, Allen BM, Spitzer MH. Systemic immunity in cancer. Nat Rev Cancer. 2021;21(6):345-59. https://doi.org/10.1038/s41568-021-00347-z.

8. Francisco LM, Salinas VH, Brown KE, Vanguri VK, Freeman GJ, Kuchroo VK, et al. PD-L1 regulates the development, maintenance, and function of induced regulatory T cells. J Exp Med. 2009;206(13):3015-29. https://doi.org/10.1084/jem.20090847.

9. Garon EB, Rizvi NA, Hui R, Leighl N, Balmanoukian AS, Eder JP, et al. Pembrolizumab for the treatment of non-small-cell lung cancer. N Engl J Med. 2015;372(21):2018-28. https://doi.org/10.1056/NEJMoa1501824.

10. Robert C, Schachter J, Long GV, Arance A, Grob JJ, Mortier L, et al. Pembrolizumab versus ipilimumab in advanced melanoma. N Engl J Med. 2015;372(26):2521-32. https://doi.org/10.1056/NEJMoa1503093.

11. Brahmer J, Reckamp KL, Baas P, Crinò L, Eberhardt WEE, Poddubskaya E, et al. Nivolumab versus docetaxel in advanced squamous-cell non-small-cell lung cancer. N Engl J Med. 2015;373(2):123-35. https://doi.org/10.1056/NEJMoa1504627.

12. Robert C, Long GV, Brady B, Dutriaux C, Maio M, Mortier L, et al. Nivolumab in previously untreated melanoma without BRAF mutation. N Engl J Med. 2015;372(4):320-30. https://doi.org/10.1056/NEJMoa1412082.

13. Fehrenbacher L, Spira A, Ballinger M, Kowanetz M, Vansteenkiste J, Mazieres J, et al. Atezolizumab versus docetaxel for patients with previously treated non-small-cell lung cancer (POPLAR): a multicentre, open-label, phase 2 randomised controlled trial. Lancet. 2016;387(10030):1837-46. https://doi.org/10.1016/S0140-6736(16)00587-0.

14. McDermott DF, Sosman JA, Sznol M, Massard C, Gordon MS, Hamid O, et al. Atezolizumab, an anti-programmed death-ligand 1 antibody, in metastatic renal cell carcinoma: long-term safety, clinical activity, and immune correlates from a phase la study. J Clin Oncol. 2016;34(8):833-42. https://doi.org/10.1200/JC0.2015.63.7421.

15. Rosenberg JE, Hoffman-Censits J, Powles T, Van Der Heijden MS, Balar AV, Necchi A, et al. Atezolizumab in patients with locally advanced and metastatic urothelial carcinoma who have progressed following treatment with platinum-based chemotherapy: a single-arm, multicentre, phase 2 trial. Lancet. 2016;387(10031):1909-20. https://doi.org/10.1016/S0140-6736(16)00561-4.

16. Chang L-S, Barroso-Sousa R, Tolaney SM, Hodi FS, Kaiser UB, Min L. Endocrine toxicity of cancer immunotherapy targeting immune checkpoints. Endocr Rev. 2019;40(1):17-65. https://doi.org/10.1210/er.2018-00006.

17. Friedman CF, Proverbs-Singh TA, Postow MA. Treatment of the Immune-Related Adverse Effects of Immune Checkpoint Inhibitors: A Review. JAMA Oncol. 2016;2(10):1346-53. https://doi.org/10.1001/jamaoncol.2016.1051.

18. Torino F, Corsello SM, Salvatori R. Endocrinological side-effects of immune checkpoint inhibitors. Curr Opin Oncol. 2016;28(4):278-87. https://doi.org/10.1097/CCO.0000000000000293.

19. González-Rodríguez E, Rodríguez-Abreu D, Spanish Group for Cancer Immuno-Biotherapy (GETICA). Immune Checkpoint Inhibitors: Review and Management of Endocrine Adverse Events. Oncologist. 2016;21(7):804-16. https://doi.org/10.1634/theoncologist.2015-0509.

20. de Filette J, Jansen $Y$, Schreuer M, Everaert H, Velkeniers B, Neyns B, et al. Incidence of thyroid-related adverse events in melanoma patients treated with pembrolizumab. J Clin Endocrinol Metab. 2016;101(11):4431-9. https://doi.org/10.1210/jc.2016-2300.

21. Delivanis DA, Gustafson MP, Bornschlegl S, Merten MM, Kottschade L, Withers S, et al. Pembrolizumab-induced thyroiditis: comprehensive clinical review and insights into underlying involved mechanisms. J Clin Endocrinol Metab. 2017;102(8):2770-80. https://doi.org/10.1210/jc.2017-00448.

22. Yamauchi I, Sakane Y, Fukuda Y, Fujii T, Taura D, Hirata M, et al. Clinical Features of Nivolumab-Induced Thyroiditis: A Case Series Study. Thyroid. 2017;27(7):894-901. https://doi.org/10.1089/thy.2016.0562.

23. Lanzolla G, Coppelli A, Cosottini M, Del Prato S, Marcocci C, Lupi I. Immune checkpoint blockade anti-PD-L1 as a trigger for autoimmune Polyendocrine syndrome. J Endocr Soc. 2019;3(2):496-503. https://doi.org/10.1210/js.2018-00366.

24. Barroso-Sousa R, Barry WT, Garrido-Castro AC, Hodi FS, Min L, Krop IE, et al. Incidence of Endocrine Dysfunction Following the Use of Different Immune Checkpoint Inhibitor Regimens: A Systematic Review and Meta-analysis. JAMA Oncol. 2018;4(2):173-82. https://doi.org/10.1001/jamaoncol.2017.3064. 
25. Das S, Johnson DB. Immune-related adverse events and anti-tumor efficacy of immune checkpoint inhibitors. J Immunother Cancer. 2019;7(1):306. https://doi.org/10.1186/s40425-019-0805-8.

26. Kotwal A, Kottschade L, Ryder M. PD-L1 Inhibitor-Induced Thyroiditis Is Associated with Better Overall Survival in Cancer Patients. Thyroid. 2020;30(2):177-84. https://doi.org/10.1089/thy.2019.0250.

27. Lima Ferreira J, Costa C, Marques B, Castro S, Victor M, Oliveira J, et al. Improved survival in patients with thyroid function test abnormalities secondary to immune-checkpoint inhibitors. Cancer Immunol Immunother. 2021;70(2):299-309. https://doi.org/10.1007/s00262-020-02664-y.

28. Yoon JH, Hong AR, Kim HK, Kang H-C. Characteristics of Immune-Related Thyroid Adverse Events in Patients Treated with PD-1/PD-L1 Inhibitors. Endocrinol Metab (Seoul). 2021;36(2):413-23. https://doi.org/10.3803/EnM.2020.906.

29. Campredon P, Mouly C, Lusque A, Bigay-Game L, Bousquet E, Mazières J, et al. Incidence of thyroid dysfunctions during treatment with nivolumab for nonsmall cell lung cancer: Retrospective study of 105 patients. Presse Med. 2019;48(4):e199-e207. https://doi.org/10.1016/j.lpm.2018.10.019.

30. Osorio JC, Ni A, Chaft JE, Pollina R, Kasler MK, Stephens D, et al. Antibody-mediated thyroid dysfunction during T-cell checkpoint blockade in patients with non-small-cell lung cancer. Ann Oncol. 2017;28(3):583-9. https://doi.org/10.1093/annonc/mdw640.

31. Iyer PC, Cabanillas ME, Waguespack SG, Hu MI, Thosani S, Lavis VR, et al. Immune-Related Thyroiditis with Immune Checkpoint Inhibitors. Thyroid. 2018;28(10):1243-51. https://doi.org/10.1089/thy.2018.0116.

32. Okada N, Iwama S, Okuji T, Kobayashi T, Yasuda Y, Wada E, et al. Anti-thyroid antibodies and thyroid echo pattern at baseline as risk factors for thyroid dysfunction induced by anti-programmed cell death-1 antibodies: a prospective study. Br J Cancer. 2020;122(6):771-7. https://doi.org/10.1038/s41416020-0736-7.

33. Petranović Ovčariček P, Verburg FA, Hoffmann M, lakovou I, Mihailovic J, Vrachimis A, et al. Higher thyroid hormone levels and cancer. Eur J Nucl Med Mol Imaging. 2021;48(3):808-21. https://doi.org/10.1007/s00259-020-05018-z.

34. Kotwal A, Gustafson MP, Bornschlegl S, Kottschade L, Delivanis DA, Dietz AB, et al. Immune Checkpoint Inhibitor-Induced Thyroiditis Is Associated with Increased Intrathyroidal T Lymphocyte Subpopulations. Thyroid. 2020;30(10):1440-50. https://doi.org/10.1089/thy.2020.0075.

35. Neppl C, Kaderli RM, Trepp R, Schmitt AM, Berger MD, Wehrli M, et al. Histology of Nivolumab-Induced Thyroiditis. Thyroid. 2018;28(12):1727-8. https://doi.org/10.1089/thy.2018.0418.

36. de Miguel M, Calvo E. Clinical Challenges of Immune Checkpoint Inhibitors. Cancer Cell. 2020;38(3):326-33. https://doi.org/10.1016/j.ccell.2020.07.004.

37. Mazarico I, Capel I, Giménez-Palop O, Albert L, Berges I, Luchtenberg F, et al. Low frequency of positive antithyroid antibodies is observed in patients with thyroid dysfunction related to immune check point inhibitors. J Endocrinol Invest. 2019;42(12):1443-50. https://doi.org/10.1007/s40618-019-01058-x.

38. Cortellini A, Bersanelli M, Buti S, Cannita K, Santini D, Perrone F, et al. A multicenter study of body mass index in cancer patients treated with anti-PD-1/PDL1 immune checkpoint inhibitors: when overweight becomes favorable. J Immunother Cancer. 2019;7(1):57. https://doi.org/10.1186/s40425-019-0527-y.

39. McQuade JL, Daniel CR, Hess KR, Mak C, Wang DY, Rai RR, et al. Association of body-mass index and outcomes in patients with metastatic melanoma treated with targeted therapy, immunotherapy, or chemotherapy: a retrospective, multicohort analysis. Lancet Oncol. 2018;19(3):310-22. https://doi.org/10.1016/S1470-2045(18)30078-0.

40. Kichenadasse G, Miners JO, Mangoni AA, Rowland A, Hopkins AM, Sorich MJ. Association Between Body Mass Index and Overall Survival With Immune Checkpoint Inhibitor Therapy for Advanced Non-Small Cell Lung Cancer. JAMA Oncol. 2020;6(4):512-8. https://doi.org/10.1001/jamaoncol.2019.5241.

41. Wang Z, Aguilar EG, Luna JI, Dunai C, Khuat LT, Le CT, et al. Paradoxical effects of obesity on T cell function during tumor progression and PD-1 checkpoint blockade. Nat Med. 2019;25(1):141-51. https://doi.org/10.1038/s41591-018-0221-5.

42. Murphy KA, James BR, Sjaastad FV, Kucaba TA, Kim H, Brincks EL, et al. Cutting Edge: Elevated Leptin during Diet-Induced Obesity Reduces the Efficacy of Tumor Immunotherapy. J Immunol. 2018;201(7):1837-41. https://doi.org/10.4049/jimmunol.1701738.

43. Pollack R, Ashash A, Cahn A, Rottenberg Y, Stern H, Dresner-Pollak R. Immune Checkpoint Inhibitor-induced Thyroid Dysfunction Is Associated with Higher Body Mass Index. J Clin Endocrinol Metab. 2020;105(10):e3620-e7. https://doi.org/10.1210/clinem/dgaa458.

\section{Figures}


Figure 1

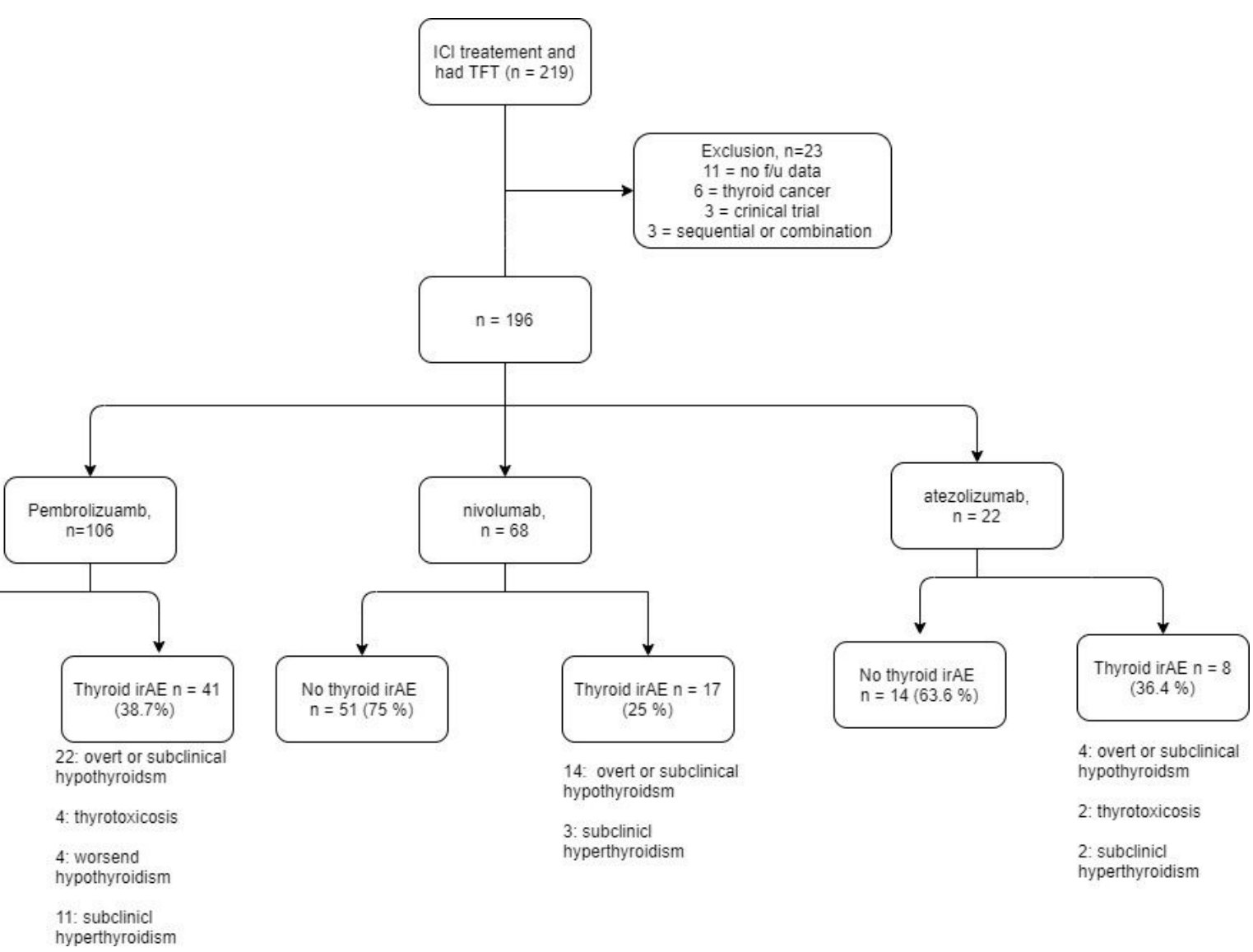

Figure 1

Flowchart of patient selection and data analysis showing the ratio of thyroid dysfunction by each ICl treatment. ICl, immune checkpoint inhibitor 
Figure 2

Survival Curve

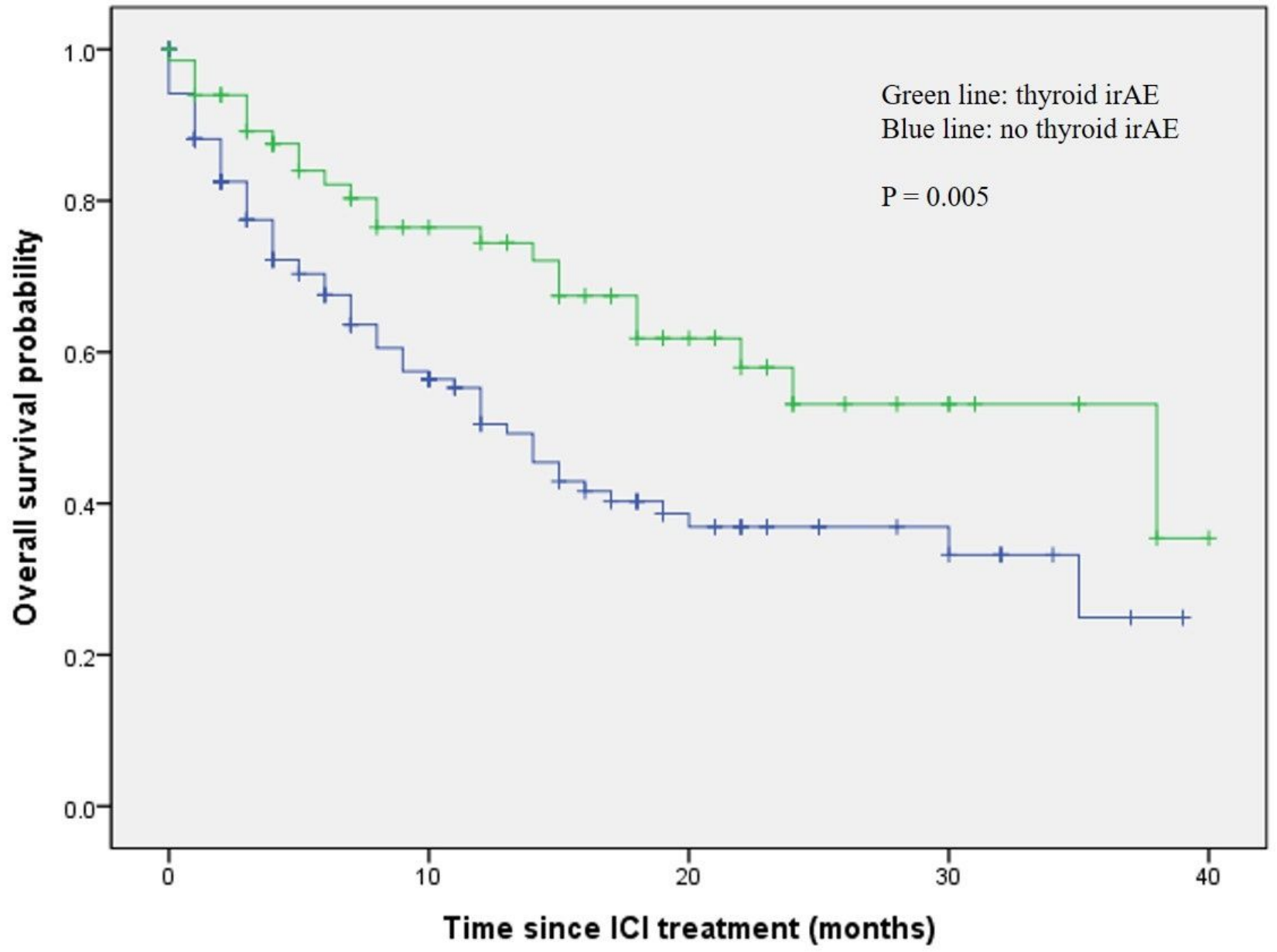

Figure 2

Kaplan-Meir survival curves of overall survival comparing between the thyroid irAE group and the no thyroid irAE group after ICI treatment. ICl, immune checkpoint inhibitor

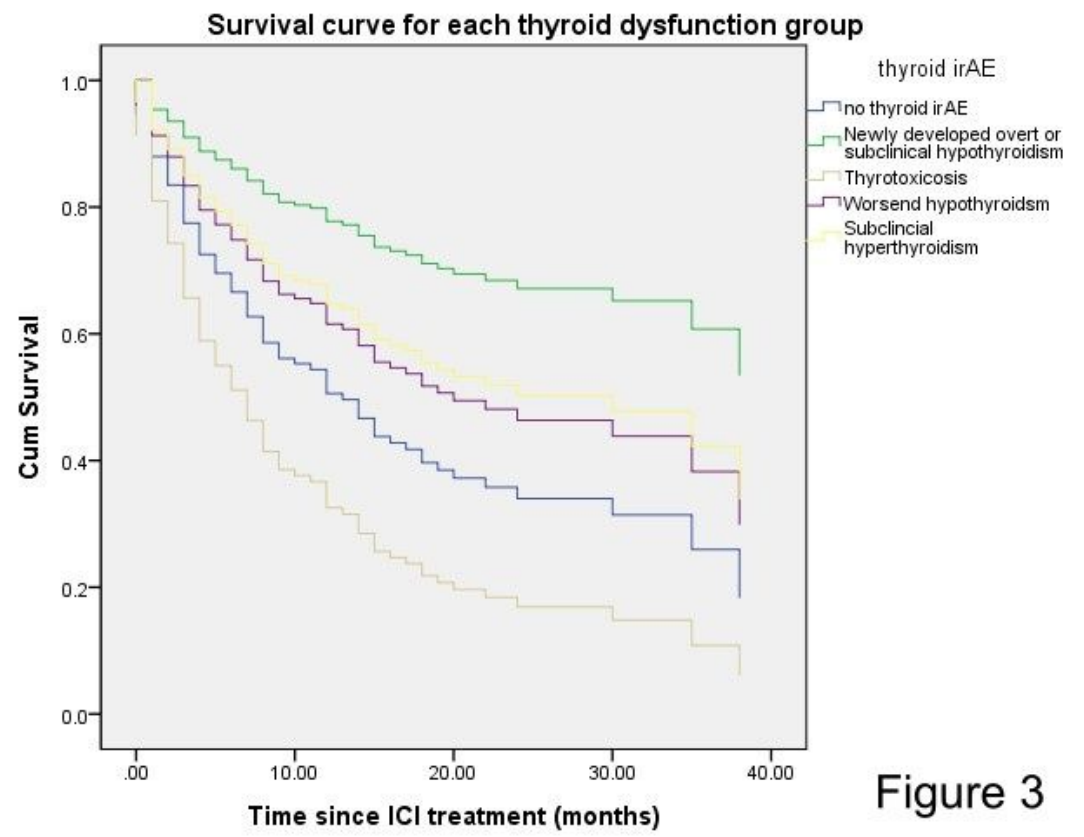

Figure 3 


\section{Supplementary Files}

This is a list of supplementary files associated with this preprint. Click to download.

- Supplementarytable1.docx 